\title{
A Six Degrees of Freedom Ship Simulation System for Maritime Education
}

\author{
Damitha Sandaruwan, Nihal Kodikara, Chamath Keppitiyagama and Rexy Rosa
}

\begin{abstract}
This paper presents Six-degrees-of-freedom ship simulation system which allows simulated ship handling under complicated environmental conditions and threat scenarios. This system simulates real-time six degrees of freedom ship motions (pitch, heave, roll, surge, sway, and yaw) under user interactions, and environmental conditions. The simulation system consists of a ship motion prediction system and a perception enhanced immersive virtual environment with greater ecological validity. This ship motion prediction system uses a few model parameters which can be evaluated by using standard ship maneuvering test or determined easily from databases such as Lloyd's register. This virtual environment supports multiple-display viewing that can greatly enhance user perception. Ecological environment for strong sensation of immersion is also developed. The virtual environment facilitates the incorporation of real world ships, geographical sceneries, different environmental conditions and wide range of visibility and illumination effects. This simulation system can be used to demonstrate ship motions, maneuvering tactics and assign focused missions to trainees and evaluate their performance. Trainees can use the simulation system to study at their own pace. Implementation and operational cost of this ship simulation system is only a fraction of the conventional training involving real ships.
\end{abstract}

\section{INTRODUCTION}

$\mathrm{S}$ hip simulations have been used for naval training, ship hull designing, simulating military scenarios and entertainment activities such as computer games [3] [11]. General naval training applications and computer games are real-time applications and therefore these applications respond in real-time for user interactions. Most of the hull designing and simulating military scenarios are non realtime applications with greater accuracy. This type of applications requires extensive computing resources because there are massive numerical equations to solve [1].

Today, ship simulations have become an essential tool in maritime education [2] [3]. Since ships have six degrees of

Manuscript received March 22, 2010. Accepted December 03, 2010.

This research was funded by the National e-Learning center, Sri Lanka and supported by Department of electrical and electronic Sri Lanka navy.

Damitha Sandaruwan is with the University of Colombo School of Computing, 35, Reid Avenue, Colombo, Sri Lanka. (e-mail: dsr@ucsc.cmb.ac.lk).

Nihal Kodikara and Chamath Keppitiyagama are also with the University of Colombo School of Computing,35, Reid Avenue ,Colombo 7, Sri Lanka.. (e-mail: ndk@ucsc.cmb.ac.lk, Chamath@ucsc.cmb.ac.lk)

Rexy Rosa is with the Department of Physics, University of Colombo, Colombo 7, Sri Lanka.. (e-mail: rosa@phys.cmb.ac.lk) freedom in ship motion as shown in Figure 1 [4], Maritime lectures in a conventional classroom can only explain ship's motions one by one, but those motions occur simultaneously. Consequently it is not easy to understand that phenomena and the resultant effects of a six degree force acting upon a vessel. A ship simulation system can be used to demonstrate complex ship motions of this nature. In a conventional maritime education system, it is not possible to create real scenarios such as terror attacks and rapid environmental changes for training purposes. In general, ship simulators are used to develop ship handling skills and strengthen theoretical understanding of ship motions in

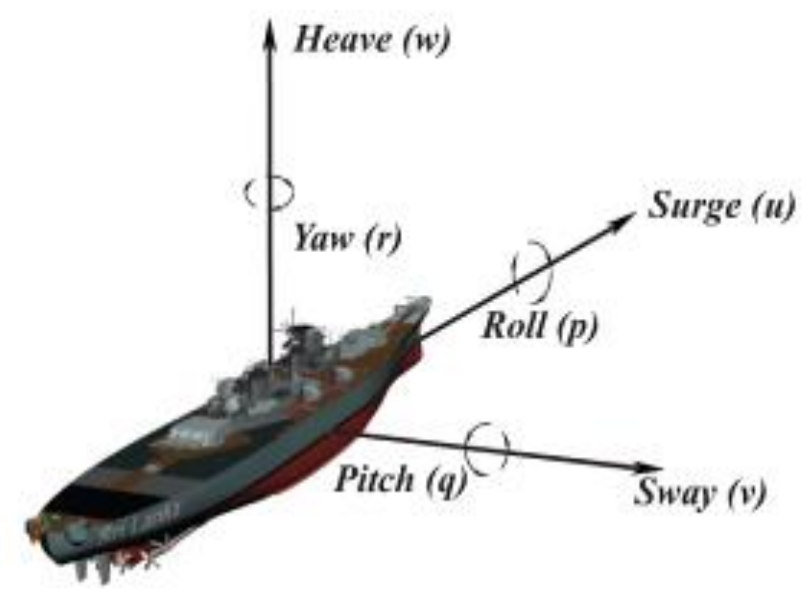

Fig. 1: Six degrees of freedom ship motions [4]

naval training. These ship simulators should respond in realtime and maintain substantial accuracy levels. When we train naval trainees to a specific mission, it is necessary to simulate real world ships, geographical areas and various environment conditions. Ecological validity is a very important factor for any virtual learning and training system [5]. Therefore, construction of tiled display system and real ship bridge gives users the real world feeling which enhances the quality of training. In ship simulation systems, learning and teaching scenarios have to be changed frequently because ship maneuvering tactics have to be changed frequently and those tactics depend on various factors such as geographical location, nature of the vessel and other environment conditions whereas, fundamental navigation and maneuvering strategies remain same.

There are commercial ship simulation systems with great ecological validity such as Transas [6] and Oceaniccorp [7]. These systems are extremely expensive, proprietary and 
closed in nature. Users can have versatile and realistic functionalities and users can customize these functionalities up to some extent [8]. However, if users try to simulate existing real world scenarios, they will face enormous restrictions because their real-time ship motion algorithms and integration mechanism of 3D objects such as vessels and navigation areas are hidden. In a ship simulation system, real-time ship motion simulation algorithms perform a major task. CPU effectiveness and accuracy of these algorithms are very important because they can affect the overall system in various perspectives. There are publicly available real-time and none real-time ship motion simulation algorithms proposed by various researchers [9] [10] [11].

There is no perception-enhanced-immersive-shipsimulation-system for marine education available under an open source license, although there are ship motion prediction systems, [10] [11], 3D virtual navigation systems based on defferent rendering engines [12] [13] [14], physics engines [15] [16] and 3D models [17] available under open source licenses. However, they are not capable of predicting reliable six degrees of freedom real-time ship motions. In addition, they have a variety of unknown complex parameters in ship motion prediction algorithms. Our approach is developed based on a reliable six degrees of freedom real-time ship motion prediction system. In this approach our ship motion prediction algorithms use limited number of parameters which can be extracted from standard maneuvering tests or databases such as Lloyd's register. We have incorporated perception enhanced tiled vision system and constructed immersive environment with greater ecological Validity. Several virtual learning and teaching scenarios for maritime education are experimented and we plan to make this total solution available under open source license.

\section{RELATED WORK}

The motion of a floating rigid body in ocean surface is extremely complicated and difficult to predict [18]. There are many real-time and none real-time ship motion prediction systems proposed by various researchers and institutes and there are different approaches to predict ship motions [9] [10] [11].

There are number of physics engines and simulation systems and game developments [15] [16]. Aspects of those physics engines are investigated. The accuracy and computational efficiency of the material properties, stacks, links, and collision detection systems are very sound but those are not capable of predicting real-time ship motions with respect to the rudder movement, throttle movement and environment conditions [15].

There are computer games such as ship simulator 2010 [19] and virtual sailor [20]. In these applications, users can select various ships, environment conditions and geographical areas associated with their object library and they can adjust principal parameters and properties of those objects. However, users cannot incorporate existing real ship or cultural objects to virtual environment and there is no capability to enhance the user perception with multiple display panels.

Some numerical algorithms are based on strip theory [21] [22]. Salvesen et al.. have presented a strip theory based method for predict heave, pitch, sway, roll and yaw motion as well as wave-induced vertical and horizontal forces blending moments and moments in regular waves [21]. Comparison between computed motions and experimental motions show satisfactory agreement in general. However, this numerical procedure is impractical for real time simulation because these strip theory based ship motion predictions need hours to produce a set of accurate solutions for just one or two motions by using modern computers. Journée present Quick Strip Theory Calculations for ship motion prediction [22]. This approach describes a strip theory based calculation method which delivers information on ship motions and added resistance within a very short computation time. A comparative validation is done but it is more suited for ship hull design and cannot be used for realtime ship motion simulations. Fossen and Smogeli presented strip theory formulation for dynamic ship motion prediction [23]. In their approach, a computer effective nonlinear time-domain strip theory formulation for lowspeed applications has been presented. The proposed model can be used to simulate real-time ship motion prediction and it is possible to incorporate the effect of varying sea states. However, the model is suited for low speed maneuvers and model parameters were evaluated by using a proprietary product.

Some other studies have been carried out for predict ship motion utilizing the Kalman Filter approach [24]. Triantafyllou et al. utilized Kalman filter techniques with simplified computational ship models for ship motion prediction. In this study, the equations of motion as derived from hydrodynamics and approximations are used with Kalman filter technique. The influence of various parameters are evaluated. However, their method requires specific model parameters, and if the ship parameters are unavailable their method is not applicable.

Xiufeng et al. developed mathematical models for realtime ship motion simulation [25]. They estimate the total forces acting on the ship first, then based on Newton's law, and then they deduce first order differential equations to model the relation between forces and accelerations. The equations are solved by using Runge- Kutta method. Their applications focus on handling ships in a selected area such as inside or near harbor areas, only the physics models for surge, sway, and yaw are given and they have not discussed the possibility to simulate existing real ships with their simulation system.

Another work is presented by Cieutat et al. [26] and they proposed wave models based on the work of Alain Fournier and William T Reeves [27]. This approach describes a new efficient real-time model of wave propagation and shows its 
integration in a real maritime simulator. They determine heave, pitch, and roll of a ship by using sea surface height under the ship. For estimating pitch and roll, the tangent plane of sea surface is computed first. Then the ship is rotated such that its orientation is aligned with the tangent plane. Their ship motion prediction algorithms are too simple and ships of different shapes will produce the same behavior if the wave condition is the same. Consequently their method is not flexible enough to simulate the behaviors of different ship models.

$X$ Zhao et al. presented a development of a high performance ship-motion prediction method [28]. Simulation results show that this method can predict ship motion with good accuracy. This is suitable for short-term motion prediction but not for longer time real-time ship motion predictions.

Ching-Tang Chou, and Li-Chen Fu presented a 6 degreeof-freedom real-time ship motion simulation system [29]. They focused on the construction of the physical dynamics of the ship on virtual reality environment. The real force and torque of ship are modeled according to Newton-Euler Formula based on the calculation of the volume below the ocean surface. They presented a new algorithm which can approach the dynamics of the ship in real-time. They introduced their real-time ship motion prediction algorithms only for Deep Ocean. They have not represented the excess drag force due to combination of yaw and sway and they did not discuss the possibility of simulating existing real ship with their virtual environment.

Gatis Barauskis and Peter Friis-Hansen presented a 3 degrees of freedom ship dynamic response model [10] which can predict surge, sway and yaw. They focused on CPU time required for ship motion prediction, ability of simulating complex non-linear models and availability of determining ship model parameters for the different type of existing ships. The model consists of a non-linear speed equation; a linear first order steering equation called Nomoto model [30] and linear sway equation. The model responds in real-time for rudder and throttle commands. This ship model is able to operate on a limited number of model parameters. Apart from the smain data of the ship, which can be TABLE I

FEATURES OF GATIS BARAUSKIS's SHIP MODEL

\begin{tabular}{|l|c|}
\hline \multicolumn{1}{|c|}{ Model Features } & Remarks \\
\hline Long term Real-time prediction & yes \\
\hline Prediction of Surge, Sway \& Heave & Surge \& Sway \\
\hline Prediction of Yaw, Pitch \& Roll & No Yaw \\
\hline Validation of Predictions & No \\
\hline Responsiveness for Wave & Yes \\
\hline $\begin{array}{l}\text { Representation of drag forces due to combined } \\
\text { yaw \& sway motion }\end{array}$ & Yes \\
\hline $\begin{array}{l}\text { Determination of Model parameters and } \\
\text { Simulation existing real ship }\end{array}$ & Not tested \\
\hline Integration with VR systems & Not tested \\
\hline Integration with immersive environment &
\end{tabular}

determined rather easily from databases such as Lloyd's register [31] ship model parameters can be estimated by using standard maneuvering tests [18]. This model represents the added mass / excess drag force due to combined yaw and sway motion but they have not done validation with respect to real world existing ships. Table 1 presents features and remarks of their model.

Ueng et al. presented efficient computational models for ship motions simulation [11]. These models are used to simulate ship movements in real time. Six degrees freedom ship motions (pitch, heave, roll, surge, sway, and yaw) are divided into two categories. The first three movements are induced by sea waves, and the last three are caused by propellers, rudders and other environment disturbances. Newtonian dynamics, fluid dynamics and other theories in physics are used to develop algorithms. This method can be used to predict real time ship motions with high CPU effectiveness. The model does not represent the added mass / excess drag force due to combined yaw and sway motion. It is a considerable deviation from the real world scenario. They have not discussed the mechanism to determine unknown model parameters and they have not done validation with respect to real world ship scenarios. Table 2 presents features and remarks of their model.

TABLE II

FEATURES OF SHYH-KUANG UENG'S SHIP MODEL

\begin{tabular}{|c|c|}
\hline Model Features & Remarks \\
\hline Long term Real-time prediction & yes \\
\hline Prediction of Surge, Sway \& Heave & Yes \\
\hline Prediction of Yaw, Pitch \& Roll & Yes \\
\hline Validation of Predictions & No \\
\hline Responsiveness for Wave & Yes \\
\hline $\begin{array}{c}\text { \&epresentation of drag forces due to combined yaw } \\
\text { existing real ship }\end{array}$ & No \\
\hline $\begin{array}{c}\text { Determination Model parameters and Simulatation } \\
\text { Integration with VR systems }\end{array}$ & Yes \\
\hline Integration with immersive environment & Not tested \\
\hline
\end{tabular}

There are a number of proposed mathematical ship models such as Tristan P'erez and Mogens Blanke [32], Tristan Perez and Thor I. Fossen [33] and Anna Witkowska et al. [34]. However, possibility of integrating those mathematical ship models with real-time applications is not discussed.

If we compare the ecological validity of above discussed ship motion simulation methods, only few approaches go towards development of 3D virtual environment [11] [29]. However, nobody has tried to develop multi display screens, physical construction of ship bridge and create immersive environment with greater ecological validity. They implement their real-time algorithms and interact with the virtual environment by using single display panel. However there are other approaches to create immersive environment with greater ecological validity [35] [36]. The researchers 
have not discussed the way of simulating existing geographical areas, real naval vessels and development of real-time ship motion algorithms.

Alexandre G. Ferreira et al. [36] presented multipledisplay Visualization system that can greatly enhance user perception specially for maritime virtual reality applications. A common approach to provide multiple synchronized display panels is to use a powerful centralized processing unit to support the rendering process on all displays. These researchers have used a different approach. The proposed distributed architecture that supports a flexible and reliable visualization system which gives users a sensation of immersion with low-end graphics workstations. The proposed system ensures the synchronization of all displayed views. Xiuwen Liu et al. have proposed a MultiProjector Tiled Display System for Marine simulator [35]. Their approach is to develop a low-cost multi projector seamless tiled display system commodity hardware and technology for the virtual reality based marine simulators. The main technical problems of the display system are discussed, including geometry distortion adjustment and edge blending. The researchers having thought about ecological validity of the virtual environment thus consequently constructed a real ship bridge and incorporated real ship bridge indicators such as radar and throttle. Experimental results in marine simulator show that this framework is very effective.

There are commercial six degrees of freedom ship simulation systems with great ecological validity such as Transas and Oceaniccorp [6] [7]. These commercial ship Simulators provide versatile and realistic ship simulation for maritime teaching, learning, assessment and research. They are capable of predicting real-time ship motions with respect to the rudder movement, throttle movement and environment conditions. However, these systems are extremely expensive and proprietary and closed systems. Consequently, their ship motion prediction algorithms and assumptions are unknown. These simulation systems enable users to simulate ship models, cultural objects and illumination effects which are associated with their object library and adjust principal parameters and properties of the objects in the object library [8]. However, users cannot incorporate existing real ship or cultural objects to the system. These commercial simulation systems have bundled teaching and learning scenarios such as "TransasPISCES2,PISCES" [37]. Users can customize these bundled teaching and learning scenarios although they cannot incorporate totally new teaching and learning materials.

After studying all these approaches we found out that the three degrees of real-time ship motion algorithms proposed by Gatis Barauskis \& Peter Friis-Hansen [10] and the six degrees of real-time ship motion algorithms proposed by Shyh-Kuang Ueng et al.[11]. are very effective from different perspectives. A combination of these two approaches can produce more effective and productive realtime six degrees of freedom algorithms. Consequently, our approach is to combine the above mentioned two algorithms to develop a more effective and productive six degrees of freedom ship motion algorithms and construct immersive virtual environment based on frameworks proposed by Alexandre G. Ferreira et al.[36] and Xiuwen Liu et al. [35]. We tested new six degrees of real-time ship motion algorithms in immersive environment with greater ethological validity and we briefly discuss the michanisum of integrating real world geographical areas and real ships.

\section{IMPLEMENTATION OF THE SIMULATION SYSTEM}

\section{A. Overview of the Integrated Simulation System}

The simulation system consists of Trainer station, Trainee station, Navigational information display system, cylindrical tiled display system, computational ship model and a database as illustrated in Figure 2. The trainer can select a vessel with predefined physical and mechanical properties and he can select geographical location's environmental conditions and threat scenarios where the trainee can essentially be trained. Navigational aids and other necessary indicators are generated and displayed on several display panels. Virtual marine scenes with own ship, moving or fixed targets, cultural objects and environmental effects are projected on to five computer screens as shown in Figure 3. This real-time vision system covers more than $270^{\circ}$ field of view from which the trainee will have the ability to maneuver the ship.

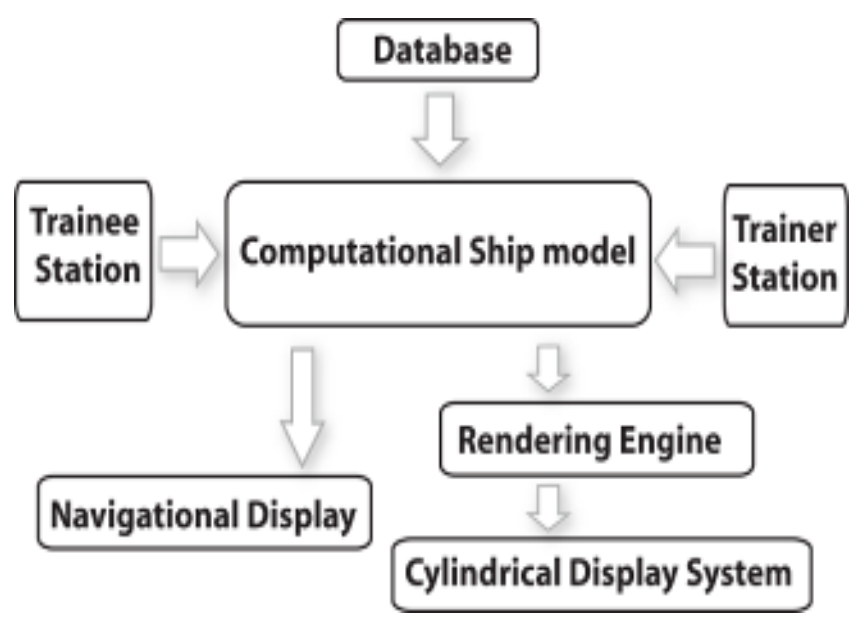

Fig. 2: Integrated Simulation System

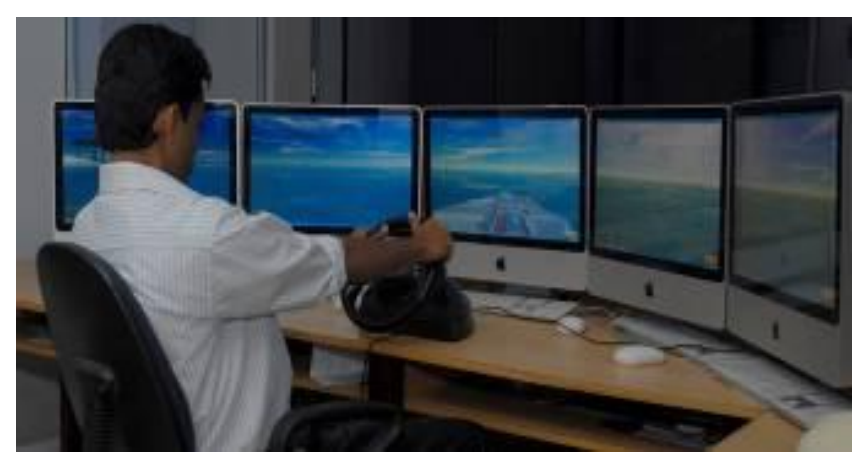

Fig. 3: Maneuvering a simulated ship 


\section{B. Computational Ship Model}

\section{1) Ship motions}

The motion of a floating rigid body can be specified by Newton's laws, fluid dynamics and other basic physics, but the motion of a floating rigid body in the ocean surface is extremely complicated and difficult to predict [18]. All six possible degrees of freedom (6DOF) in a motion of a ship can be illustrated as in Figure 1. Surge, heave, and sway are translational motions. Roll, yaw, and pitch are rotational motions [4].

Following assumptions were made in order to simplify the mathematical ship model for real-time challenges.

- The pitch, heave and roll motions are caused by sea waves. Surge, sway, and yaw motions are induced by internal and external forces such as rudders, propellers and environment conditions such as wind and sea currents.

- Figure 4 and 5 illustrate the initial earth-fixed reference frame with $\left[\begin{array}{ll}\mathrm{x} & \mathrm{y} z \\ \mathrm{z}\end{array}{ }^{\mathrm{T}}\right.$ coordinate system and the ship body-fixed reference frame with $\left[\mathrm{x}_{0} \mathrm{y}_{\mathrm{o}}\right.$ $\mathrm{z}_{\mathrm{o}}{ }^{\mathrm{T}}$ coordinate system [9]. Ship body-fixed axes coincide with the principal axes of inertia. Origin of the ship body-fixed frame coincide with the center of gravity of the $\operatorname{ship}\left(\mathrm{r}_{\mathrm{G}=}\left[\begin{array}{lll}0 & 0 & 0\end{array}\right]^{\mathrm{T}}\right)$ [9].

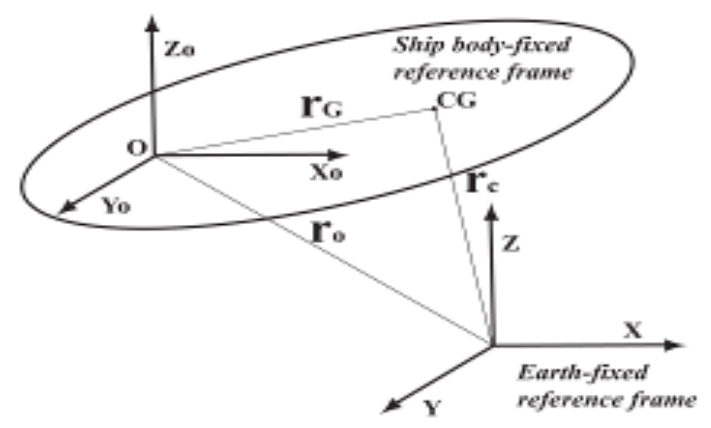

Fig. 4: Reference frames and coordinate systems [9]

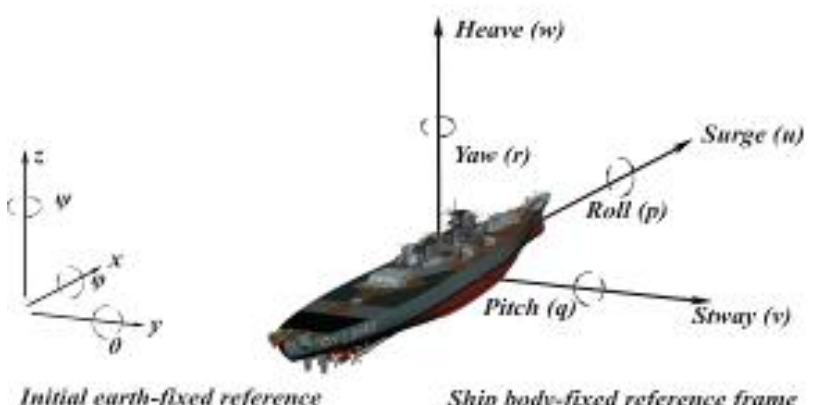

Initial eardh-fixed reference

Ship body-fixed reference frame

Fig. 5: Reference frames \& coordinate systems [9]

- The ship is rigid and impossible to deform. The shape of the ship is identical to a cubical.

- The sea waves consist of sinusoidal waves and waves can apply force and moments (Torque) on the ship. However, ship cannot influence the wave.
- The variation of the sea surface is less than or equal to $8^{\text {th }}$ level of the Beaufort's sea state scale [18].

The magnitudes of the position, orientation, forces, moments, liner velocities and angular velocities are respectively denoted by $\left[\begin{array}{lll}x & y & z\end{array}\right]^{\mathrm{T}},\left[\begin{array}{lll}\psi & \theta & \varphi\end{array}\right]^{\mathrm{T}},\left[\begin{array}{lll}X & Y & Z\end{array}\right]^{\mathrm{T}},\left[\begin{array}{ll}K & M\end{array}\right.$ $N]^{\mathrm{T}},\left[\begin{array}{lll}u & v & w\end{array}\right]^{\mathrm{T}}$ and $\left[\begin{array}{lll}p & q & r\end{array}\right]^{\mathrm{T}}$ as shown by Table1. The position-orientation vector in the $\mathrm{XY}$ plane is expressed as $\eta=\left[\begin{array}{lll}\mathrm{x} & \mathrm{y} & \psi\end{array}\right]^{\mathrm{T}}$ and the linear-angular velocity vector is expressed as $v=\left[\begin{array}{lll}\mathrm{u} & \mathrm{v} & \mathrm{r}\end{array}{ }^{\mathrm{T}}\right.$. The rate change of Positionorientation vector is expressed as $\dot{\eta}=R(\psi) v$ [32] where

$$
\mathrm{R}(\psi)=\left[\begin{array}{ccc}
\operatorname{Cos} \psi & -\operatorname{Sin} \psi & 0 \\
\operatorname{Sin} \psi & \operatorname{Cos} \psi & 0 \\
0 & 0 & 1
\end{array}\right] .
$$

TABLE III

Six Possible Degrees of FreEdom SHIP Motion [4]

\begin{tabular}{|c|c|c|c|}
\hline $\begin{array}{c}\text { Degrees } \\
\text { of freedom }\end{array}$ & $\begin{array}{c}\text { Forces } \\
\text { Moments }\end{array}$ & $\begin{array}{c}\text { Linear/Angular } \\
\text { Velocities }\end{array}$ & $\begin{array}{c}\text { Positions } \\
\text { Euler Angles }\end{array}$ \\
\hline Surge & $\mathrm{X}$ & $u$ & $X$ \\
\hline Sway & $\mathrm{Y}$ & $v$ & $Y$ \\
\hline Heave & $\mathrm{Z}$ & $w$ & $Z$ \\
\hline Yaw & $\mathrm{N}$ & $r$ & $\Psi$ \\
\hline Pitch & $\mathrm{M}$ & $q$ & $\Theta$ \\
\hline Roll & $\mathrm{K}$ & $p$ & $\Phi$ \\
\hline
\end{tabular}

2) Wave Model

We use the multivariable ocean wave model introduced by Ching-Tang [38] to model the sea surface and determine the height field of the sea surface. In that model,

$h(x y t)=\sum_{i=1}^{n} A_{i} \operatorname{sink}_{i}\left[\left(x \cos \theta_{i}+y \sin \theta_{i}\right)-\omega_{i} t+\varphi_{i}\right]$

Above function represents a water surface height on the $\mathrm{Z}$ axis direction. $A$ is the wave amplitude, $k$ is the wave number where this number is defined as $2 \pi / \lambda$ by the wave length $\lambda$. $\omega$ is the pulsation which is defined as the $2 \pi \mathrm{f} b y$ the frequency $\mathrm{f} . A, k$, and $\mathrm{f}$ are time (t) dependent variables. $\theta$ is the angle between $\mathrm{X}$ axis and the direction of the wave. $\varphi$ is the initial phase which can be selected randomly between $0-2 \pi$.

\section{3) Surge Motion}

The surge motion of a ship is described by a simplification of the non-linear speed equation as follows [9].

$M \dot{u}=T_{e}-X_{u|u|} u|u|-\left(M+X_{v r}\right) v r$

In equation (3) $M$ and $T_{e}$ respectively denote the ship's mass and single driving force (effective propeller thrust) that is transmitted from the ship engine by her propellers. The two terms $X_{u|u|} u|u|$ and $\left(M+X_{v r}\right) v r$ can be regarded as damping forces, which depend on the instantaneous dynamics of the vessel. $\left(M+X_{v r}\right) v r$ represents excess drag force due to combined yaw and sway motion $X_{u|u|} u|u|$ correspond to the quadratic resistance force at the forward 
speed $u$. When the ship is traveling a straight course and at a constant speed $\quad u, \quad\left(M+X_{v r}\right) v r=0$ and $O=T_{e}-X_{u|u|} u|u|$. Then, if we know $T_{e}$ and $u$ then it is possible to calculate the $X_{u|u|}$. The force of the propeller is related to its revolution speed $n$ and the diameter $D$ and the thrust coefficient $K_{t}$ and it is given by $T_{e}=K_{t} n^{2} D^{4}$ [39], $X_{v r}=0.33 M[32]$.

\section{4) Yaw Motion}

The yaw motion of the ship is described by using the first order Nomoto model and the transfer function from rudder angle $\delta$ and rate change of turn $r$ is equivalent to the time domain differential equation as follows [9] [30].

$$
\tau \dot{r}+r=K \delta
$$

$K$ is the steady-state gain of the system and $\tau$ is the time constant. $K$ and $\tau$ can be calculated by using Maneuver Tests [18]. This model behaves more accurately within the linear region of a ship's steering function up to rudder angles of approximately 35 degrees. [39] [9]

\section{5) Sway Motion}

Sway motion is considered based on the transfer function model with constant parameters. It is equivalent to the time domain differential equation given below [9] [30].

$$
\tau_{v} \dot{v}+v=K_{v}(\tau \dot{r}+r)
$$

$K_{v}$ is the steady-state gain in sway and $K_{v}$ is the time constant in sway. The time constant and the steady state constant have been assumed to be $K_{v}=.0 .5 \mathrm{l}$ and $\tau_{v}=$ $0.3 \tau$ [10] [9].

\section{6) Motions Caused by Sea Waves}

By solving the equation (1),(3),(4) and (5) we can compute the ship's position orientation vector in the $\mathrm{XY}$ horizontal plane with respect to time. That means we can calculate $x, y, u, v$ and $\psi$. Then according to Archimedes' principle [40] we assume the translational motion (heave) and rotational motions (pitch, and roll) are generated by the swellness of water under the ship. It can be calculated by using the height variation of the sea surface. We assume that the shape of the ship is cubical as illustrated in Figure 6 and the ship body is vertically projected onto the sea surface to get the $l \times w$ bounding box. It is divided in to $1 m \times 1 m$ cells for mathematical convenience as illustrated in Figure 7.

We evaluate the height fields at center points of each $1 m \times 1 m$ cells and we assume the ship is not actually presented when the height field is calculated. We can use Ching-Tang's wave model [38] to calculate height fields. We assume that the projected bounding box and its points move with the ship. Then, any time we can calculate height fields according to ship's orientation and the wave propagation. We can obtain forces and moments to generate the heave, pitch and roll motions by calculating the height fields for overall bounding box, calculating difference of height fields between the front and rear halves of the bounding box and calculating difference of height field between the Port and starboard halves of the bounding box respectively.

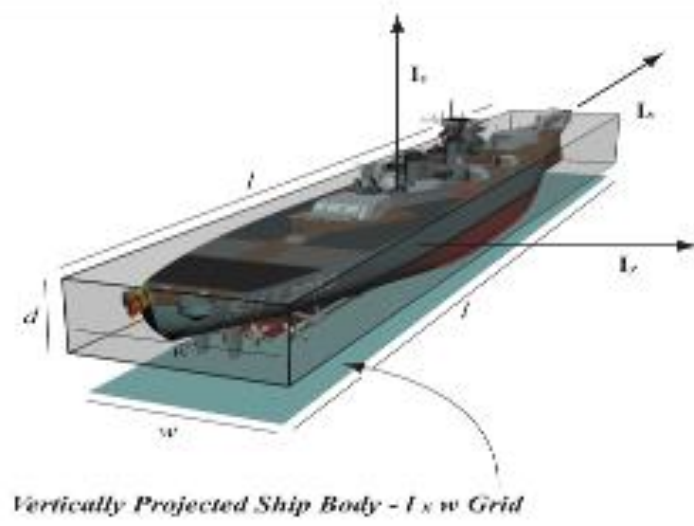

Fig. 6: The shape of the ship is identical to a cubical

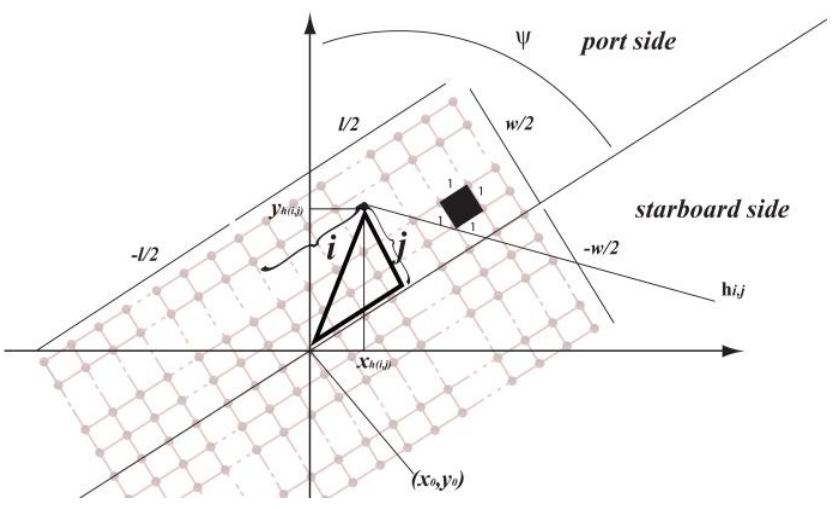

Fig. 7: Vertically projected ship body $(1 \times \mathrm{w}$ grid $)$

\section{7) Heave Motion}

First we calculate the vertical variation (height fields) of each $1 m \times 1 m$ cells. If the sum of height fields is not zero the swell of the sea surface generate the force to raise up or pull down the ship. The sum of height fields is $H_{a}$ and $h_{i, j}$ denote the height field of $(i, j)$ point with respect to vertically projected ship body ( $l \times w$ grid). When we know the ship's position in XY plane $\left(x_{o}, y_{o}\right)$ and the heading (Euler Angle) with respect to positive $X$-axis $(\psi)$, we can compute the earth fixed coordinate $\left(x_{h i, j}, y_{h i, j}\right)$ for each and every ship fixed coordinate $h_{i, j}$ in vertically projected ship body ( $l \times w$ grid) as illustrated in Figure 4. The height field of $(i, j)$ point in the vertically projected ship body is equivalent to the height field of $\left(X_{h_{(i, j)}}, Y_{h_{(i, j)}}\right)$ point in earth fixed coordinate system. Height fields of earth fixed coordinates can be calculated by using Ching-Tang's wave model [38]. i.e. $h(i, j, t)=h\left(X_{h(i, j)}, Y_{h(i, j)}, t\right)$

$X_{h(i, j)}=\sqrt{i^{2}+j^{2}} \operatorname{Sin}(\psi-\alpha)$

$Y_{h(i, j)}=\sqrt{i^{2}+j^{2}} \cos (\psi-\alpha)$

$\alpha=\tan ^{-1} j / i$.

The sum of height fields in vertically projected ship body $(1 \times w$ grid $)$

$H_{a}=\sum_{i=\frac{-l}{2}}^{\frac{l}{2}} \sum_{j=\frac{-w}{2}}^{\frac{w}{2}} h_{i, j}$. 
The force for heave motion can be calculated by multiplying the sum of the height fields and Sea water density $\left(S_{w}\right)$. The net force for heave motion $\left(F_{h}\right)$ can be calculated by subtracting the resistance force $\left(R_{h}\right) \cdot K_{h}$, $M, \dot{w}, w$ denote the resistance coefficient for heave motion, Mass of the ship, heave acceleration and heave velocity [16]. The equations are listed below.

$$
\begin{aligned}
& R_{h}=K_{h} M|w|^{2} \\
& F_{h}=H_{a} S_{w}-R_{h} \\
& \dot{w}=F_{h} / M \quad \dot{w} \Delta t=\Delta w
\end{aligned}
$$

\section{8) Pitch Motion}

Here, we assume that pitch is determined by the difference of height field between front and rear halves of the ship. $H_{p}$ is the height field deference between the front and rear halves of the ship.

$H_{p}=\sum_{i=\frac{l}{2}}^{\frac{l}{2}} \sum_{j=\frac{-w}{2}}^{\frac{w}{2}} h_{i, j} \frac{i}{|i|}$

By using Ching-Tang's wave model [38], $h_{i, j}$ can be calculated. Then the net force for pitch $\left(F_{p}\right)$, pitch angular acceleration $(\dot{q})$ and pitch angular velocity $(q)$ is determined as follows:

$$
\begin{aligned}
& R_{p}=K_{p} I_{p} q \\
& F_{p}=H_{p} S_{w}-R_{p} \\
& \dot{q}={ }^{F_{p}} / I_{p} \quad \dot{q} \Delta t=\Delta q
\end{aligned}
$$

$S_{w}, K_{p}, R_{p}, I_{p}$ denote the sea water density, resistance coefficient for pitch motion, resistance force against pitch motion and the ship's moment of inertia along Y-axis respectively. For mathematical convenience we have already assumed the shape of the ship is cubical as Figure 6 shown.

then $I_{p}=\frac{1}{12} M\left(l^{2}+d^{2}\right)$.

\section{9) Roll Motion}

Here we assume that roll is determined by the difference of height field between the port side and starboard side halves of the ship. $\mathrm{H}_{r}$ is the height field deference between the port side and starboard side halves of the ship.

$H_{r}=\sum_{i=\frac{-l}{2}}^{\frac{l}{2}} \sum_{j=\frac{-w}{2}}^{\frac{w}{2}} h_{i, j} \frac{j}{|j|}$

Then as we did in the pitch motion calculations we can calculate net force for roll motion, roll angular acceleration and roll angular velocity.

10) Overview of the computational ship model

The system consists of two major stages. First stage is to compute ship's position and orientation in XY plane by using ship's physical data, user defined dynamic properties
(Rudder, Engine RPM) and resistance forces due to motion. The second stage is to compute heave, pitch and roll motion by using the out puts of the first stage and additionally considering the ocean wave model as illustrated in Figure 8. In this system, we use constraints, coefficients and parameters like $K, \tau, K_{p}, K_{h}$ which can be evaluated with a standard maneuvering test or figure out from a databases such as Lloyd's register [31].

11) Validate surge, sway and yaw motions

Our ship motion prediction algorithms are more suitable for ocean surface vehicles which approximately box type geometric formations. Our surge, sway and yaw real-time ship motion prediction algorithms were validated with respect to benchmark sea trials of the "Esso Ossaka Tanker" [41].

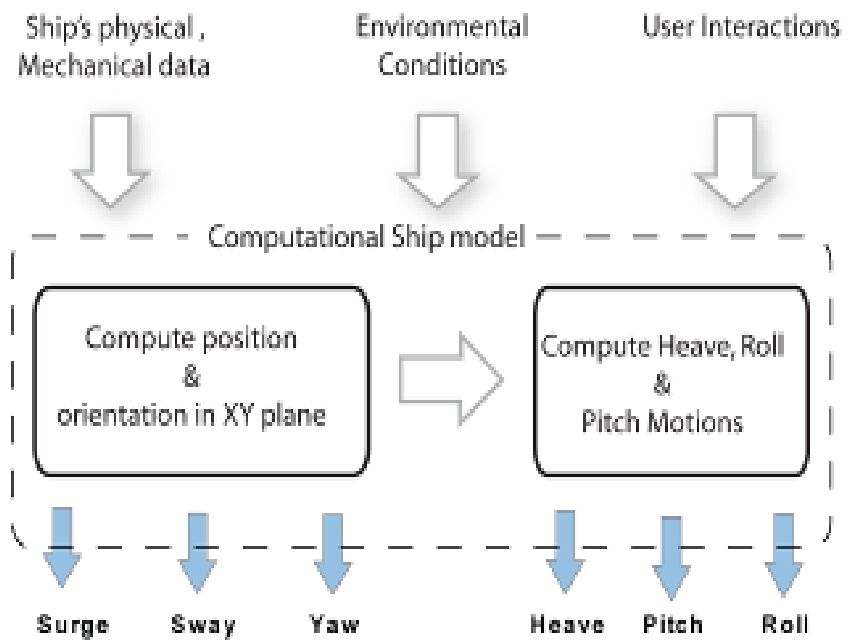

Fig. 8: Computational Ship model

Esso Osaka is a tanker with approximately box type geometric formation as shown in the Figure 9.

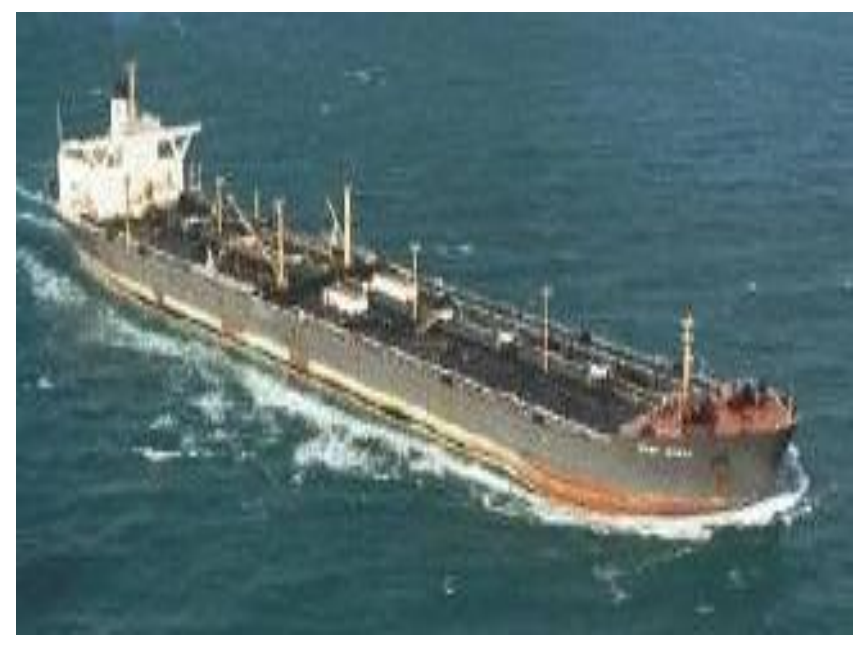

Fig. 9: Esso Ossaka Tanker [41]

It is an oil tanker that has been used for extensive maneuvering studies in the open literature [42]. Main particulars for the Esso Osaka are Length (between perpendiculars) $-325 \mathrm{~m}$, Beam $-53 \mathrm{~m}$, draft $-21.73 \mathrm{~m}$, Displacement- 4 319,400 tonnes. Propulsion characteristics are propeller diameter $-9.1 \mathrm{~m}$ and when the propeller 
rotates at $51 \mathrm{RPM}$ the ship travels at 10 knots in calm water. The propeller thrust coefficient Kt is 0.004 [43] [44]. Figures 10 to 12 present measured turning circle data for the Esso Osaka with initial velocities of 10 knots.

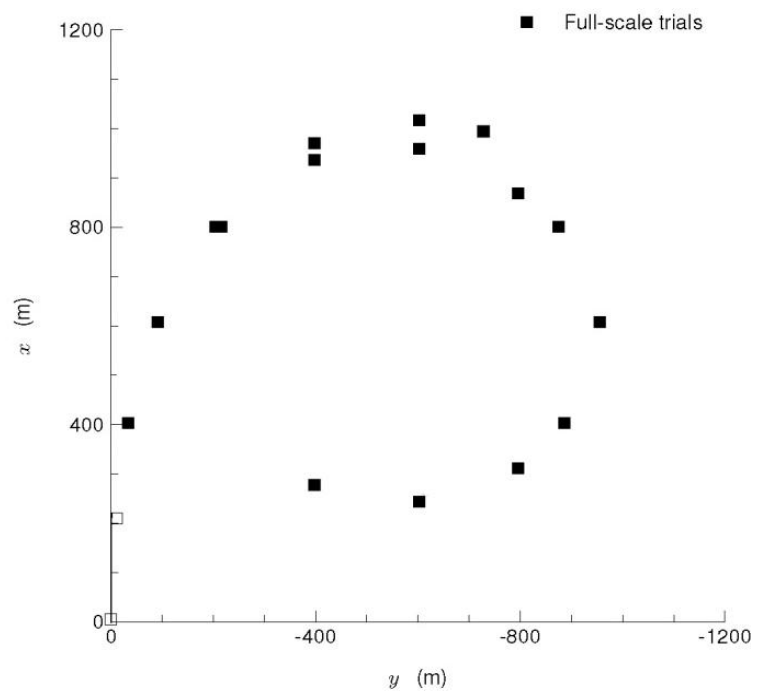

Fig. 10: Trajectory for Esso Osaka Turn at 10 Knots with 35 degree Rudder [43]

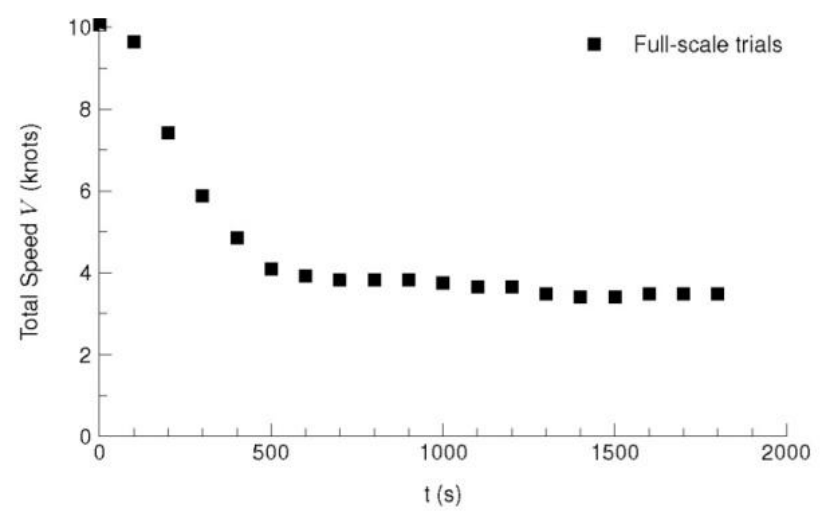

Fig. 11: Yaw Rate Versus Time for Esso Osaka Turn at 10 Knots with 35 degree Rudder [43]

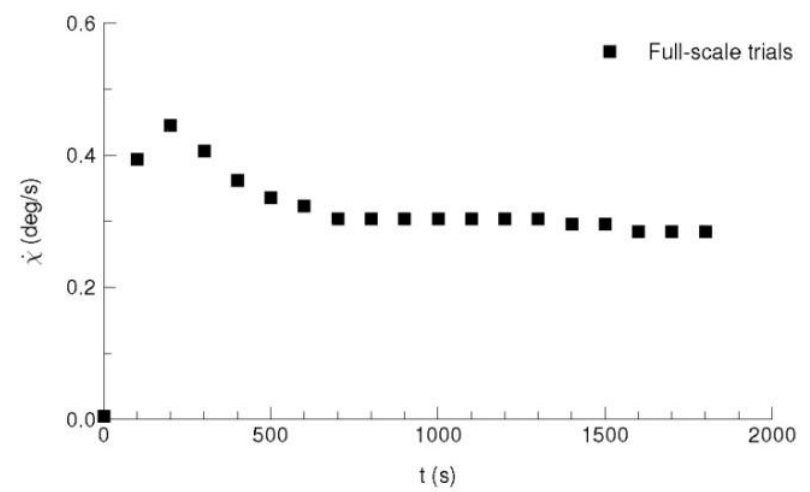

Fig. 12: Ship Speed Versus Time for Esso Osaka Turn at 10 Knots with 35 degree Rudder[43]

By using the Esso Osaka's main particulars, propulsion characteristics and the above real sea trial data set it is possible to determine our model parameters $X_{u|u|}, K$ and $\tau$. However, due to unavailability of some resistance and propulsion properties we had to model them using approximations based on data in the open literature [43] [44]

After determining the model parameters, we simulated the same turning circle under similar conditions in our simulation system. We used MATLAB [45] solvers to solve deferential equations in our real-time algorithms and 2.66GHz Intel Core 2 Duo iMac to run our computational ship model. Comparison of the real Esso Osaka turning circle and simulated turning circle is shown in the Figure 13.

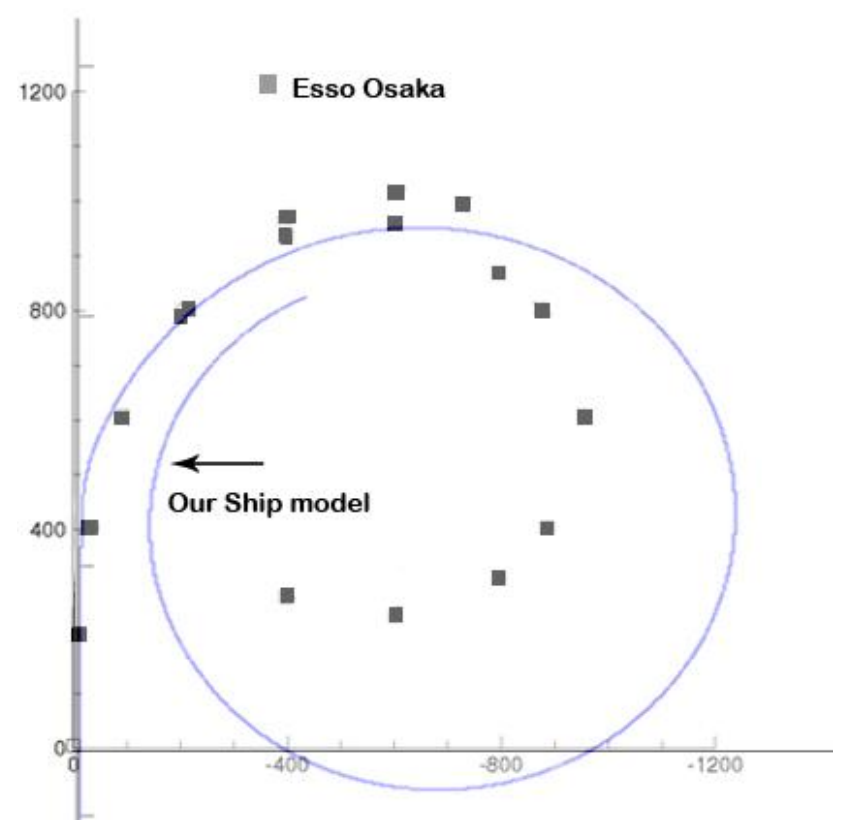

Fig. 13: Validation with respect to "Esso Ossaka" sea trials

Comparison of predicted and measured ship motions gives encouraging outcomes. We predicted these ship motions under several assumptions as mentioned in the Section "B". Simulating the real world scenario in a virtual world with similar conditions could lead to practical issues. We cannot create exactly similar real world environment and conditions in the virtual world and the rate change of the mechanical properties such as rudder and throttle are extremely difficult to imitate in a virtual world. We approximated several parameters based on literature. When we consider all these factors there should be deviations in simulated results and real world situations.

12) Validate heave, pitch and roll motions

The relationship between ship motion and the ocean wave characteristics is commonly measured by using the Response Amplitude Operators (RAO) [46] [47]. Figure 14 present the typical heave RAO for a floating body on ocean

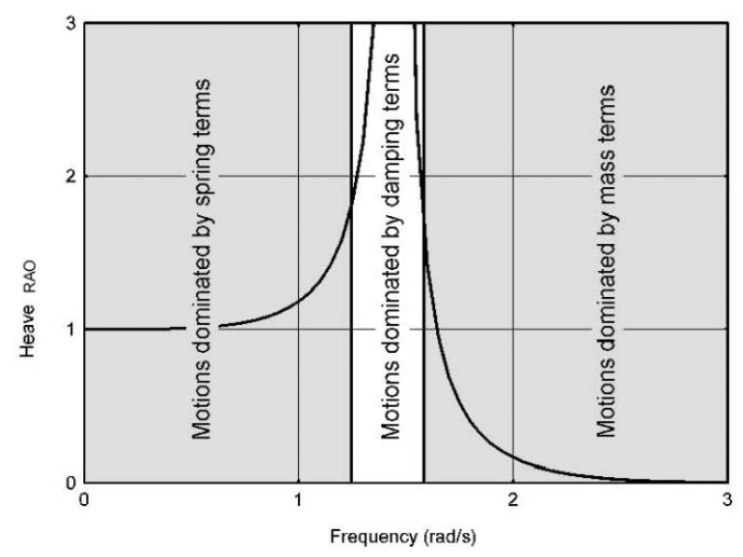

Fig. 14: Typical heave RAO behavior with respect to wave frequency [18] 
wave [18]. Figure 15 and Figure 16 present the typical pitch and roll RAO curves for a containership with respect to wave frequency at different ship speeds [18].

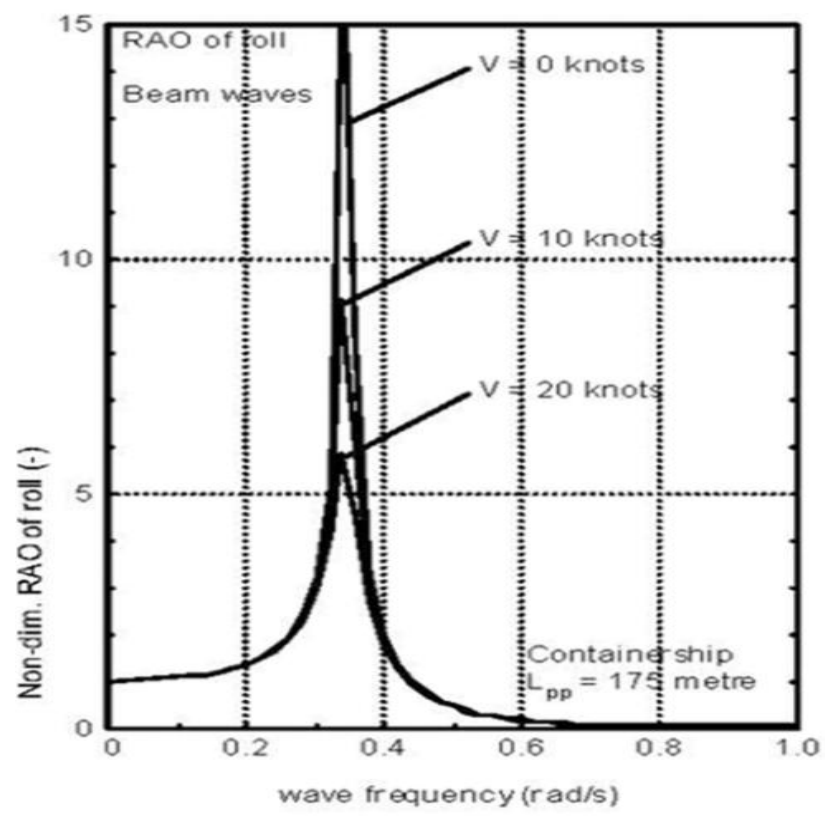

Fig. 15: Typical roll RAO behavior with respect to wave frequency [18]

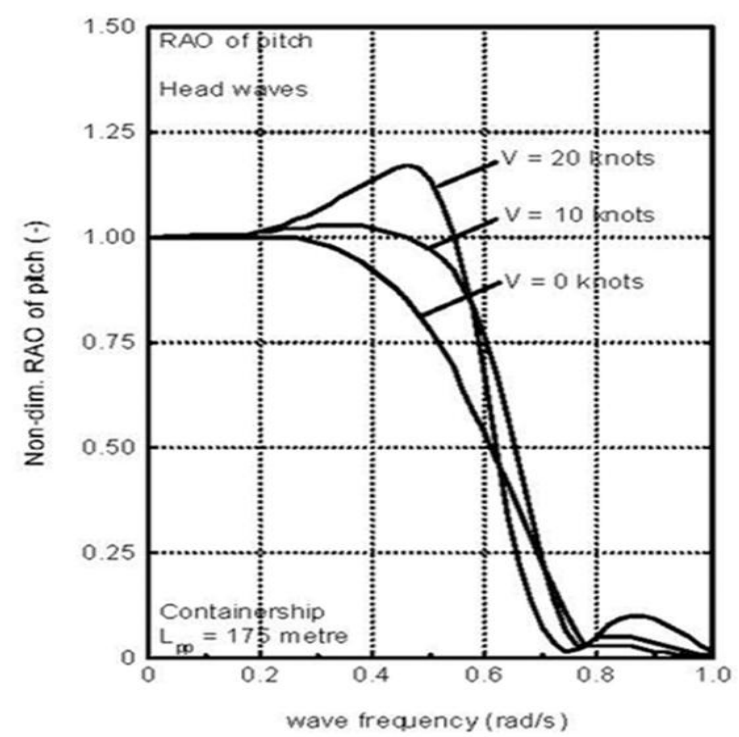

Fig. 16: Typical pitch RAO behavior with respect to wave frequency [18]

Due to unavailability of heave, pitch and roll resistance coefficients for "Esso Osaka" we had to assume reasonable values for them using approximations. Today it is very easy to measure heave, pitch and roll for a real ship in sea way because there are digital devices such as OCTANS surface motion sensor [48]. If we can measure heave, pitch and roll under known condition then we can determine resistance coefficients for heave, pitch and roll motions. We measured RAOs for "Esso Osaka" ship model with respect to different domains however there is no unclassified real sea trial RAO data set for "Esso Osaka" to compare with our ship motion predictions. We measured RAOs for steered Esso Osaka at 6 knots, encountered wave direction 30 , wave amplitude $0.5 \mathrm{~m}$ and wave length $0.5 \mathrm{~m}$. The nature of the RAO curves are presented in Figure 17,18 and 19.

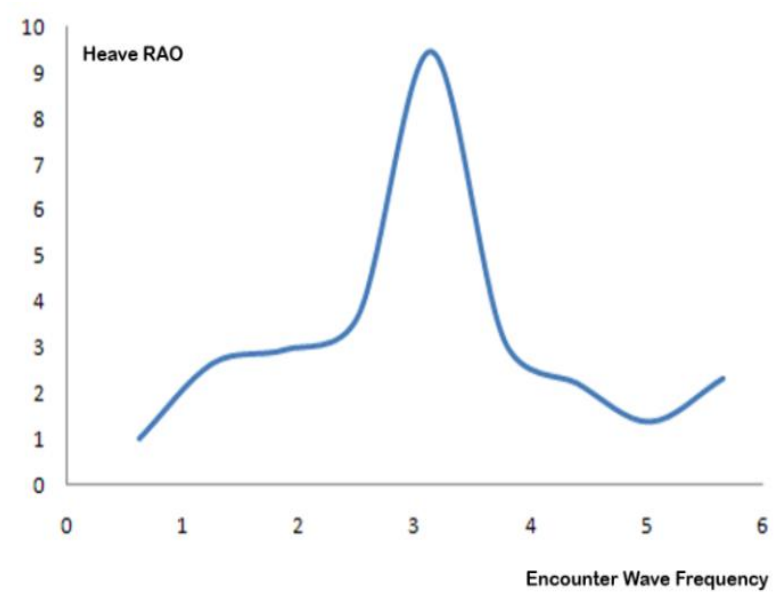

Fig. 17: Observed heave RAO behavior with respect to wave

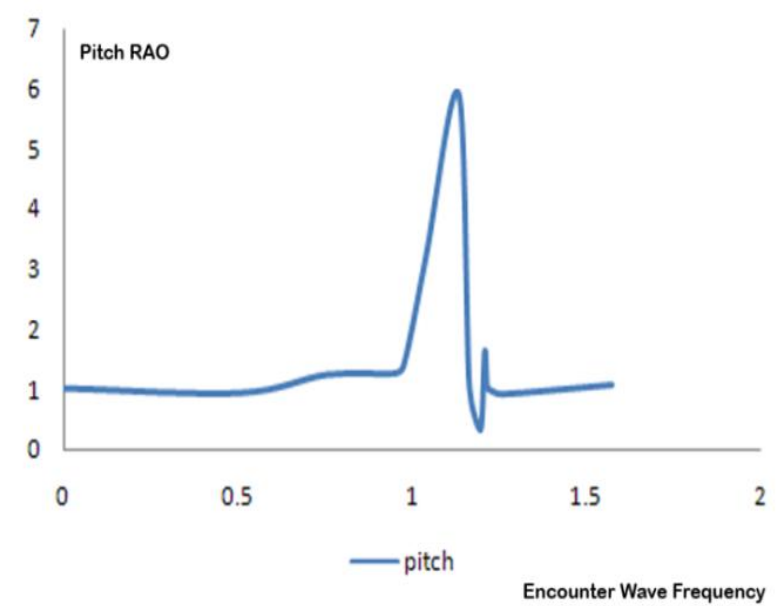

Fig. 18: Observed pitch RAO behavior with respect to wave frequency

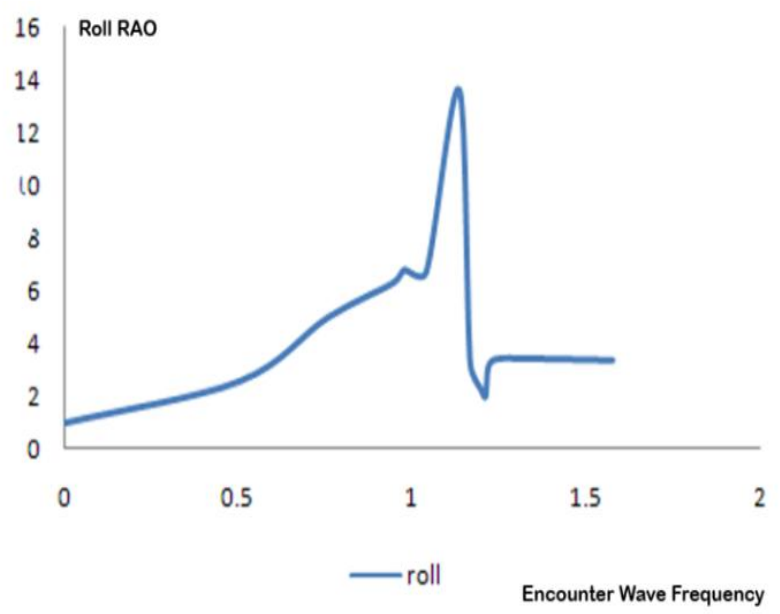

Fig. 19: Observed roll RAO behavior with respect to wave frequency

The comparison of typical RAO curves of a container ship and obtained RAO curves of "Esso Ossaka" does not give any significant result. However there are some common futures in higher level comparisons. Throughout these experiments we assumed ship's hull formation is a cuboid .However motion of a ship is affected by the geometry of the ship hull [49]. In the ocean wave model we consider only the most responsive wave component consequently it is a deviation from the real scenario and we 
approximated several parameters. When we consider all these factors there should be a deviation in simulated results and real world situation. According to experiment results, features of the proposed computational ship model are present in table 4.

TABLE IV

FEATURES OF PROPOSED SHIP MODEL

\begin{tabular}{|c|c|}
\hline Model Features & Remarks \\
\hline Long term Real-time prediction & yes \\
\hline prediction of Surge, Sway \& Heave & Yes \\
\hline prediction of Yaw, Pitch \& Roll & Yes \\
\hline Validation of Predictions & Yes \\
\hline Responsiveness for Wave & Yes \\
\hline $\begin{array}{l}\text { Representation of drag forces due to combined yaw } \\
\text { \& sway motion }\end{array}$ & Yes \\
\hline $\begin{array}{l}\text { Determine Model parameters and Simulate existing } \\
\text { real ship }\end{array}$ & Yes \\
\hline Integration with VR systems & Yes \\
\hline Integration with immersive environment & Yes \\
\hline
\end{tabular}

13) Panoramic Vision System

Panoramic images and videos are regularly used in various virtual reality applications such as autonomous navigation and virtual walkthroughs [35] [36]. This visionsystem is based on the client-server architecture. It supports real-time six degrees of freedom autonomous navigation system with $300^{\circ}$ field of view. The server computer sends the navigational instructions (latitude, longitude, altitude, roll, pitch, and yaw) to the six the client computers as shown in Figure 20.

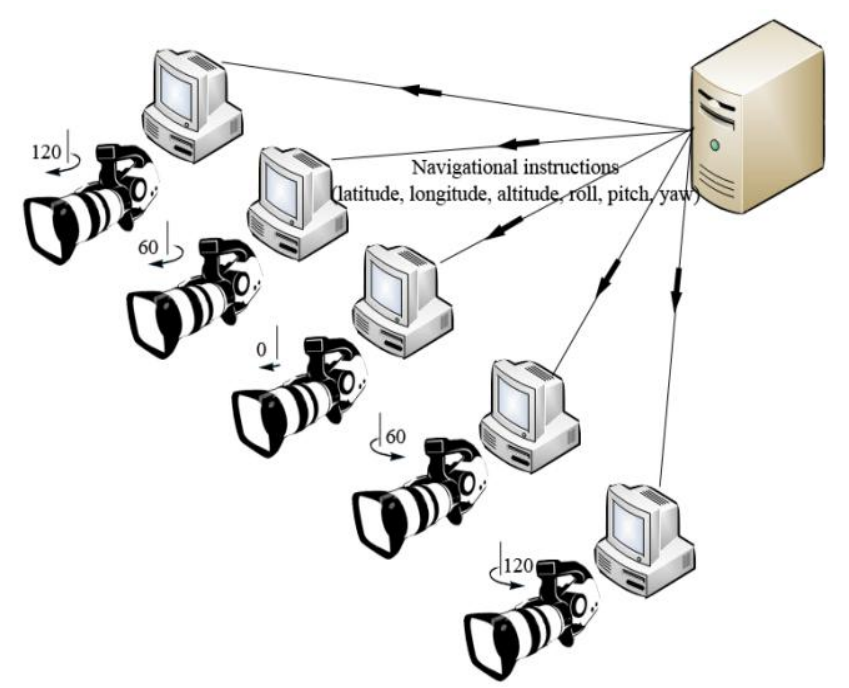

Fig. 20: Structure of the vision system

In each client computer, the same virtual environment is loaded and the position and the orientation values received by a parental node. Each virtual camera inherits its position and orientation from the parental node while maintaining 60 degrees with respect to adjacent virtual cameras. To create tile $300^{\circ}$ field of view (FOV) each virtual camera occupies $60^{\circ}$ angle of view [12]. Navigational instructions (latitude, longitude, altitude, roll, pitch, yaw) are sent to virtual cameras from the master computer over the network.
We develop a method to synchronize each virtual camera. The sever computer send data set containing latitude, longitude, altitude, roll, pitch, yaw simultaneously to each client computer through the network. Each and every client PC should pace the virtual camera according to the given position and orientation and render the scenery. After completing the rendering process each client machine should send a message to sever computer. Thereafter the sever computer sends the next navigational instruction data set after acquiring all six messages from the client computers. This synchronization mechanism reduces the frame rate a little, but the above mentioned $2.66 \mathrm{GHz}$ Intel Core 2 Duo iMacs with NVIDIA GeForce 9400M graphic cards were able to maintain more than 25 Frames per second with complex scenery.

\section{Database}

In this ship simulation system we use our own computational ship models based on our algorithms so that we can incorporate any computational ship model to our database which satisfies our algorithms and constrains. We have developed several six degrees of freedom computational ship models such as benchmark tanker "Esso Ossaka" and offshore patrol vessel quite identical to "Jayasagara" class which has been locally built by the Colombo dockyard [50]. We used Ogre3D rendering engine which has capability of realistic ocean wave rendering [51]. to create real-time interactive environment [52] and incorporated real world geographical sceneries with cultural objects, moving/ fixed targets, several environmental conditions and wide range of visibility and illumination effects such as daytime, dusk and night were incorporated into our database.

We modeled a Sri Lankan harbor and incorporated into our data base based on the method proposed by Philip Paar etl [53]. We used British admiralty charts of "Galle harbor and approaches" as shown in the Figure 21 [54] and Google earth [55] images shown in the Figure 22 for the $3 \mathrm{D}$ modeling.

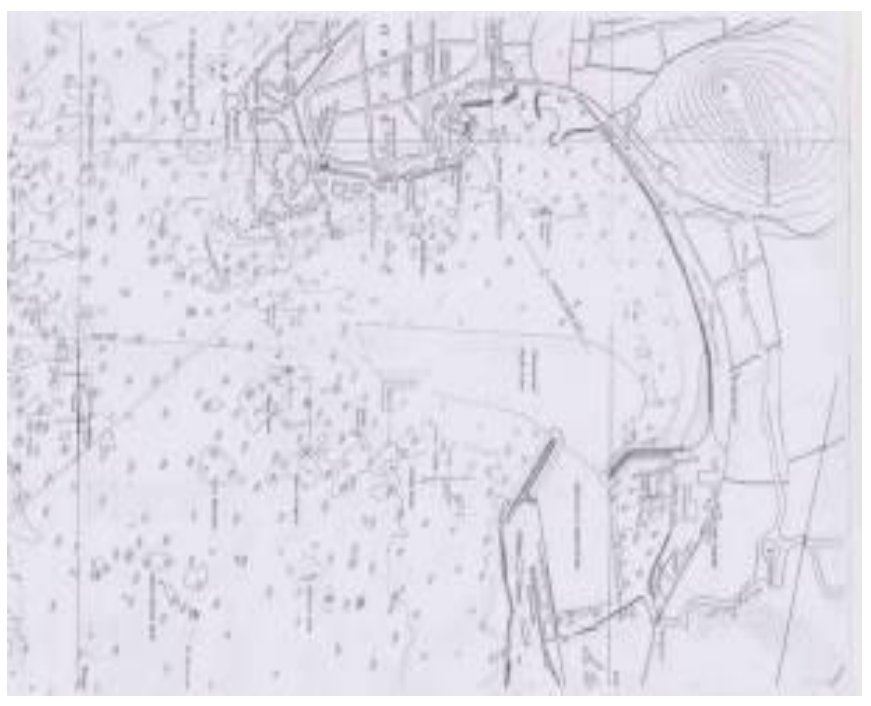

Fig. 21: "Galle harbor" navigational map 


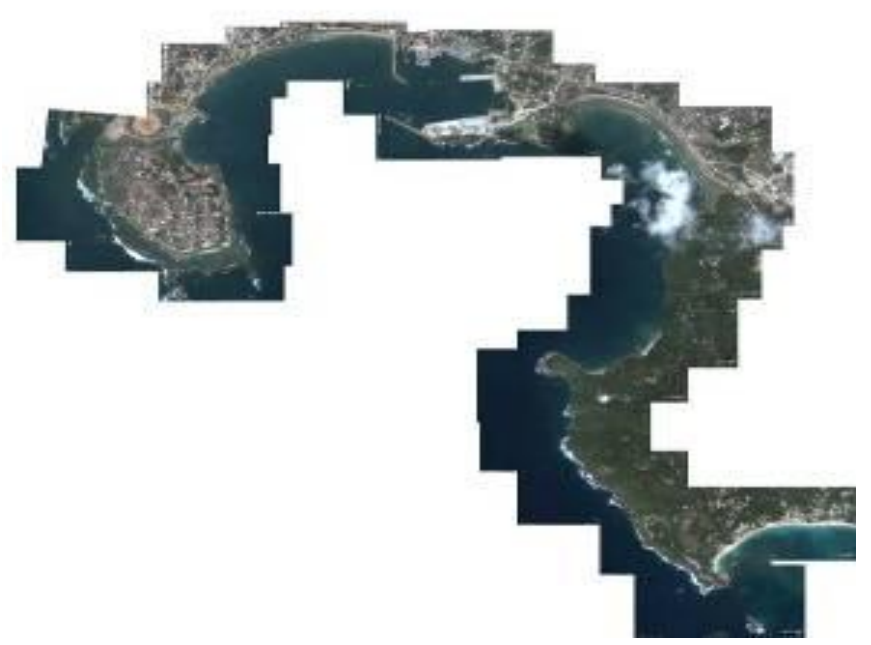

Fig. 22: Top view of the selected harbor

Subsequently the shore line was finalized and sequent digital pictures were taken from sea while keeping the same distance from the shore line.

Same process was repeated several times to get different image sequences with different distances from the shore line. Various moving and fixed targets and cultural objects were observed in the sea around the selected harbor. The relative sizes of the observed object were recorded with respect to a selected earth fixed object and digital pictures were taken from different distances.

We used 3D studio max [56] to create mesh models. All naval vessels, moving or fixed targets, and cultural objects, scenes of navigation areas were modeled using 3D studio max. When modeling the navigation areas and the shore line major objects were modeled with polygonal meshes and the other objects were placed by using the billboards. Throughout this 3D modeling we used appropriate textures to model more realistic scenery. Most of the time we captured the real texture from the digital camera and it was then enhanced by image editing software. Several times we used standard materials from the 3D studio max library. We used OgreMax Scene Exporter to export the modeled scenery from 3D studio max to Ogre 3D. The OgreMax Scene Exporter [57] is a 3DS Max plugin that exports 3DS Max scenes to OgreMax scene files. Finally the virtually created environment is compared with the real environment.

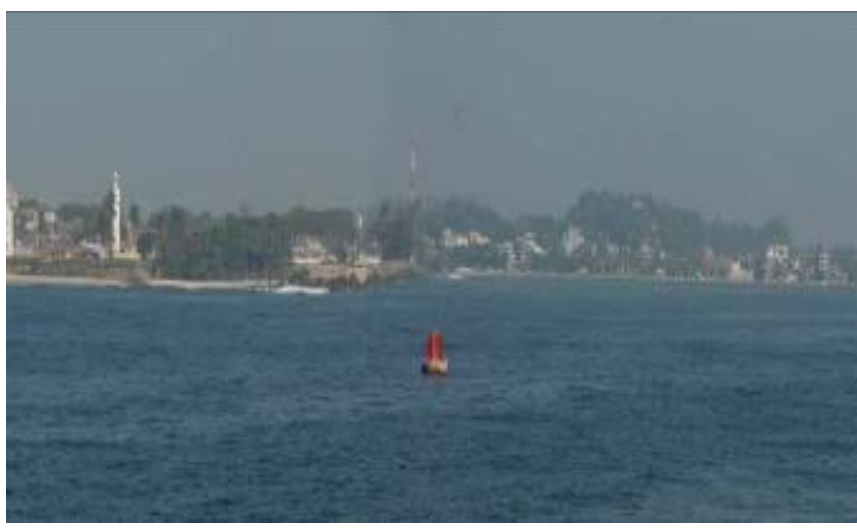

Fig. 23: Real harbor environment
The outcome is quite satisfactory as shown in the Figure 23 and Figure 24.

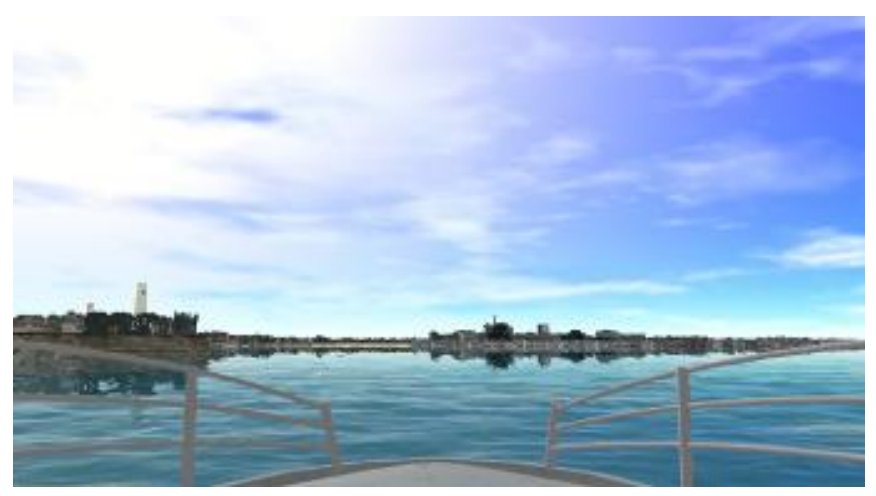

Fig. 24: Virtually created harbor environment

\section{DEVELOPMENT OF IMMERSIVE ENVIRONMENT}

The immersive environment is composed of 4 standard game PCs - (3 clients and a server) and multi projector seamless tiled display system. It was constructed using three multimedia projectors with 2500 ANSI lumens. This large polygonal screen projected realistic visuals with wide field of view and a real scale bridge was constructed and placed as shown in the Figure 25. This brings a sense of seriousness and realism to the users perception hence this is strengthening the ecological validity of the environment.

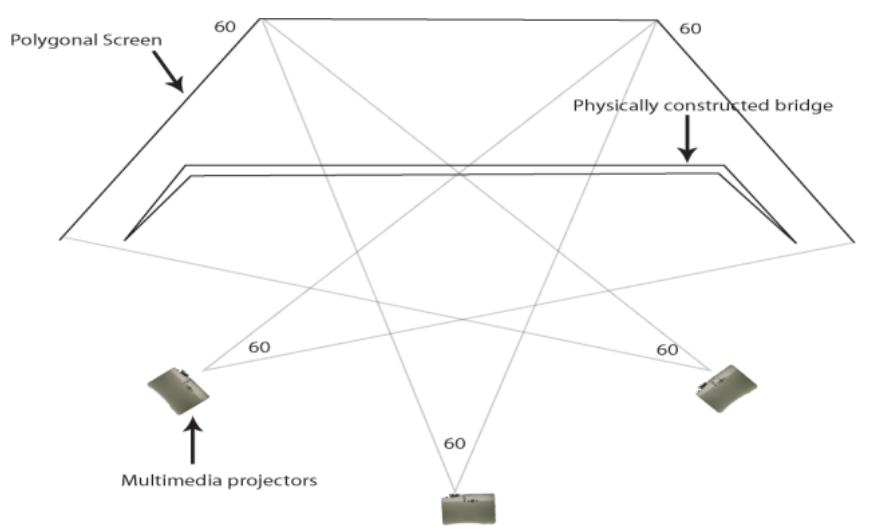

Fig. 25: Bridge and projector arrangement

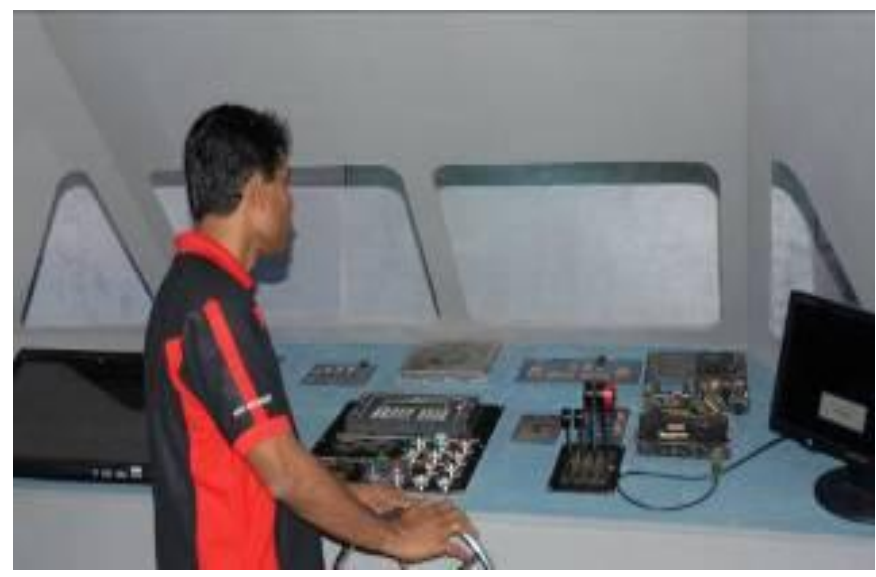

Fig. 26: Physically built ship bridge 
Discarded real equipments were integrated in to the bridge. In this case, real throttle and wheel were interfaced to provide a more realistic virtual environment and a strong sense of immersion as shown in Figure 18. The total cost for equipments and construction of ecological environment is less than 2, 000, 000 Sri Lankan rupees. This perception enhanced virtual environment was exhibited in several national and international level exhibitions as shown in Figure 19. Large number of people including naval experts, sailors, Navy officers, national and international researchers, game lovers and general public used this immersive environment.

According to the feedback from naval experts who has more than 15 years maritime experience with Sri Lankan navy ships, we noted that there is a good agreement for surge, sway and yaw motion simulations with respect to the real scenario. There are some divergences in heave, pitch and roll motion simulations with respect to the rendered ocean wave pattern. However we were able to achieve the desired perception of naval experts by changing several model parameters which are related to heave, pitch and roll motion simulation.

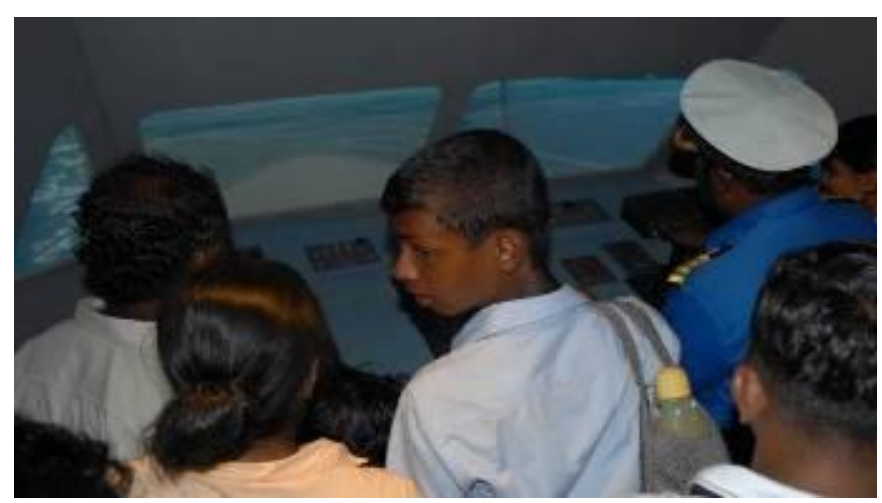

Fig. 27: Virtual environment in an exhibition

\section{TEACHING AND LEARNING SCENARIO}

There are three kinds of learning and training scenarios where the simulator can be used.

- In class, teaching of theoretical aspects of navigation and ship motion.

- Train people for a particular mission and evaluate their performance.

- Self learning.

In marine education, theoretical understanding of ship motions is essential. Variety of phenomena occur simultaneously in short time duration, including drift, turning, speed reduction, drift angle, heading. The trainer can use the simulation system and demonstrate those ship motions real-time. Trainer can select a ship, geographical scene of the navigation area, cultural objects, moving/ fixed targets, environmental conditions. He can demonstrate ship maneuvering tactics and the use of the navigational display consisting of radar, sonar, 2D map, engine RPM indicator and the rudder angle indicator. The trainer can also demonstrate how to deal with various threat scenarios. Then trainer can define various missions with different difficulty levels for trainee to gain and understand ship maneuvering skills. While the trainee is maneuvering the ship the trainer can change difficulty levels and threat scenarios. After several training sessions the trainer can be given specific missions and his performance evaluated.. Trainees can use the simulation system and select ship, geographical scenery, define his own difficulty levels and study at their own pace. These learning scenarios enhance the teaching and learning experience.

\section{A. Sample learning activity}

A basic learning activity is developed with the help of the navel experts from the Sri Lanka Navy according to their fundamental navigation lessons with real ships.

\section{Lesson Title: Basic Navigation}

Simulated Ship: offshore patrol vessel (Ship's length, beam, draft, mass and maximum effective thrust are respectively $48 \mathrm{~m}, 8.6 \mathrm{~m}, 2.2 \mathrm{~m}, 35.6 \times 10^{4} \mathrm{Kg}$ and $15.0 \mathrm{x}$ $\left.10^{4} \mathrm{~N}\right)$, Sea State: Beaufort Sea state 3, Present geographical location is given, Mission: Cast off the ship from the present location and proceed to given location and anchorage within given time frame.

Trainee has to use the simulation system. Geographical map of the navigation area as shown in Figure 20 and parallel ruler are provided. Several learning activities were carried out with navel experts to experiment our simulation system and further identify learning and teaching requirements.

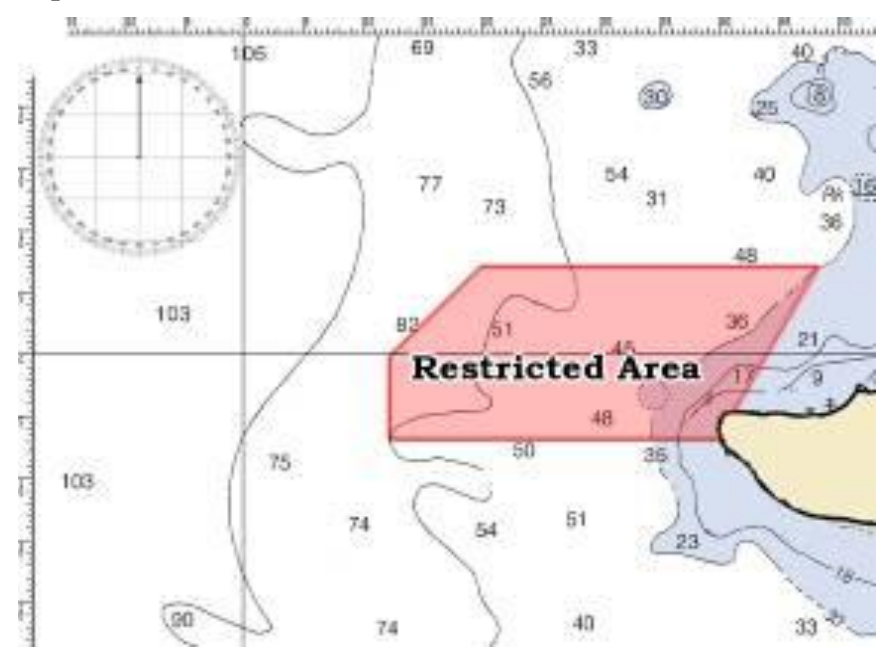

Fig. 28: Geographical map of the navigation area

\section{FUTURE WORK}

We had to consider existing real ship and perform maneuvering tests and measure necessary motions by using electronic devices. Subsequently we can evaluate model parameters without approximations. This will lead to a perfect six degrees of freedom validation of our ship motion simulation. We had to further develop the computational 
ship model for simulate various kind of modern ships with multiple propellers.

Seamless cylindrical tiled display system should be developed to further enhance the trainee's perception. Image stitching and blending algorithms [58] have to be used to get the desired output which is going to be projected on a semi cylindrical projection screen by using the multimedia projectors. Then the trainee can get a more immersive maritime experience. Development of a real-time acoustic model for the current simulation system will enhance the ecological validity of the simulated environment. In order to use this simulation system in a wide range of teaching and learning scenarios we had to incorporate more naval vessels, moving or fixed targets, cultural objects, scenes of navigation areas, various environmental effects and conditions to the existing database.

We had to conduct experiments with navel experts to further identify the trainee's and trainer's requirements. Consequently, various training scenarios had to be designed in order to develop a more productive and efficient virtual learning and training environment. Development of a learning Management System that could monitor trainee, trainer and training activities is essential.

It seemed that the accuracy of the roll, pitch and heave motion simulation do not have great impact for several training scenarios such as traffic handling and off show navigations. Consequently, we are planning to conduct further research to develop a training oriented computational ship model for educational activities based on human perception and other important factors such as biological, physiological and sociological aspects.

\section{CONCLUSION}

Experimental results show that the proposed six degrees of freedom ship motion simulation algorithms have different capabilities with respect to the algorithms proposed by Gatis Barauskis and Peter Friis-Hansen presented [10] and ShyhKuang Ueng et 1 [11]. Specially, we tested our ship motion prediction algorithms in immersive environments and validated the motion predictions with respect to real world scenarios. Surge, sway and yaw motion predictions show some satisfactory results however roll, pitch and heave motion predictions do not give any satisfactory results. However, there are some encouraging observations in higher level explorations.

The performed learning and training scenarios indicate that current simulation system can be used to select training scenarios such as navigation training and sea traffic handling. Experience gained through this kind of ship simulation system enables students to understand the dynamic mechanism behind ship motion. It is possible to create virtual scenarios such as motion of enemy ships and rapid environmental changes for training purposes which are not possible in conventional ship maneuvering training done in real sea environment with real ships. Naval trainers can use this system for in-class-teaching of selected theoretical aspects of navigation and ship motion. In addition, trainers can train trainees for particular missions and evaluate their performances. Trainee can use the system and define various tactical scenarios within different difficulty levels so that they can learn at their own pace. Implementation cost of current simulation system is less than 2000USD and running cost of this ship simulation system is minimal. However, operating cost of tanker ship per day is more than 2000USD [59]. Consequently, with respect to conventional training involving real ships, this ship simulation system reduces the total cost of training and increases the quality of training.

Experimental results show that the proposed framework is very effective for a virtual maritime learning and training purposes and it is scalable and comparable to industry standard full scale simulators with perception enhanced cylindrical vision system. We plan to make this ship simulation system available under an open source license so that anyone can customize or further develop it according to their requirements.

\section{ACKNOWLEDGMENT}

Our thanks go to Department of Electrical and Electronics, Sri Lanka Navy and National e-learning Center, Sri Lanka for their collaborative support.

\section{REFERENCES}

[1] Biran, A B., Ship Hydrostatics and Stability. Oxford OX2 8DP Butterworth-Heinemann, 2003. ISBN 0750649887.

[2] Ergun Demirel, Romesh Mehta., "Developing an Effective Maritime Education and Training System- TUDEV." ACCRA-GHANA : s.n., 2009. IMLA CONFERENCE.

[3] Woolley, Mark., "Time for the Navy to Get into the Game!" Proceedings Magazine, U.S Naval Institiute. 2009, Vols. 135/4/1,274, April.

[4] Society of Naval Architects and Marine Engineers ., Nomenclature for treating the motion of a submerged body through a fluid. New York : The Society of Naval Architects and Marine Engineers, 1950.

[5] Albert A. Rizzo, Todd Bowerly, J. Galen Buckwalter, Dean Klimchuk, Roman Mitura,Thomas D. Parsons., "A Virtual Reality Scenario for All Seasons The Virtual Classroom." CME 3. January, 2006.

[6] Transas Marine Limited., Transas Simulation Products. [Online] Transas Marine International. [Cited: 06 06, 2010. http://www.transas.com/products/simulators/.

[7] Oceanic Consulting Corporation., Centre for Marine Simulation. [Online] http://www.oceaniccorp.com/FacilityDetails.asp?id=7.

[8] Transas Marine International., Transas Database editor Model Wizard. Transas. [Online] [Cited: May 06, 2010.] http://www.transas.com/products/simulators/sim_products/navigation al/components/tools/.

[9] Fossen, Thor I., Guidance and Control of Ocean Vehicles. England : Jhon Wiley, 1996. ISBN: 0471941131.

[10] Gatis Barauskis, Peter Friis-Hansen., "FAST-TIME SHIP SIMULATOR." 2007. Safety at Sea 2007.

[11] Shyh-Kuang Ueng, David Lin, Chieh-Hong Liu., "A ship motion simulation system." s.1. : Springer-Verlang, 2008. Virtual Reality (2008). pp. 65-76.

[12] Junker, Gregory., Pro OGRE 3D Programming. s.l. : Apress, 2006. ISBN-13: 978-1590597101. 
[13] Irrlicht Realtime 3D Engine. [Online] [Cited: May 06, 2010.] http://irrlicht.sourceforge.net/index.html.

[14] Gaming and Simulation Engine. [Online] [Cited: May 06, 2010.] http://www.delta3d.org/.

[15] Adrian Boeing, Thomas Bräunl., "Evaluation of real-time physics simulation systems." Perth, Western Australia: ACM Press, 2007. GRAPHITE 2007. pp. 281-288. ISBN: 9781595939128.

[16] PhysX., physxinfo.com. Popular Physics Engines Comparison PhysX, Havok and ODE. [Online] [Cited: May 06, 2010.] http://physxinfo.com/articles/?page_id=154.

[17] Free Downloads 3D Models. [Online] [Cited: May 06, 2010.] http://www.3dmodelfree.com/.

[18] Pinkster, J.M.J. Journée and Jakob., Introduction in Ship Hydromechanics. s.l. : Delft University of Technology, 2002.

[19] Ship Simulator Extremes. [Online] [Cited: May 06, 2010.] http://www.shipsim.com/.

[20] Virtual Sailor. [Online] [Cited: May 06, 2010.] http://www.hangsim.com/vs/.

[21] Nils Salvesen, E. O. Tuck and O. Faltinsen., Ship Motion and Sea Loads. New York: Society of Naval Architects and Marine Engineers, 1970.

[22] Journée, J.M.J., "Quick Strip Theory Calculations in Ship Design." Newcastle upon Tyne: s.n., 1992. Practical Design of Ships and Mobile Structures. Vol. 1.

[23] THOR I. FOSSEN, ØYVIND N. SMOGELI., "Nonlinear TimeDomain Strip Theory Formulation for Low-Speed Manoeuvring and Station-Keeping." Modelling, Identifica- tion and Control MIC. 2004 Vol. 25.

[24] Michael S Triantafyllou, Marc Bodson, Michael Athans., "Real Time Estimation of Ship Motions Using Kalman Filtering Techniques." IEEE JOURNAL OF OCEANIC ENGINEERING, January 1983, Vols. OE-8, pp. 9-20.

[25] Zhang Xiufeng, Jin Yicheng, Yin Yong, Li Zhihua., "Ship simulation using virtual reality technique." Singapore : ACM, 2004. 2004 ACM SIGGRAPH international conference on Virtual Reality continuum and its applications in industry. pp. 282 - 285 . ISBN:1-58113-884-9.

[26] J. M. Cieutat, J. C. Gonzato, P. Guitton., "A New Efficient Wave Model for Maritime Training Simulator." Budmerice, Slovakia : IEEE Computer Society Washington, DC, USA, 2001. 17th Spring conference on Computer graphics. p. 202 . ISBN 0-7695-1215-1.

[27] Alain Fournier, William T. Reeves., "A simple model of ocean waves." ACM SIGGRAPH Computer Graphics, s.1. : ACM New York, NY, USA, 1986, Issue 4, Vol. 20, pp. 75 - 84 . ISSN:00978930.

[28] X Zhao, R Xu, C Kwan., "Ship-motion prediction: algorithms and simulation results." 2004. ICASSP '04- IEEE International Conference on Acoustics, Speech, and Signal Processing. ISBN: 07803-8484-9.

[29] Ching-Tang Chou, Li-Chen Fu., "VR-based Motion Simulator for Dynamics Ship on Six Degree-of-Freedom Platform." Roma, Italy : s.n., 2007. ICRA International Conference. SBN: 1-4244-0601-3.

[30] Chen, Ching-Yaw Tzeng and Ju-Fen., "Fundamental Properties of Linear Ship Steering Dynamic Models." Journal of Marine Science and Technology, 1997, Vol. 7.

[31] Lloyd's Register., Lloyd's Register. [Online] [Cited: May 06, 2010.] http://www.lr.org.

[32] Tristan Perez, Mogens Blanke., Mathematical Ship Modeling for Control Applications. 2002.

[33] Tristan Perez, Thor I. Fossen., "Kinematic Models for Seakeeping and Manoeuvring of Marine Vessels." Modeling, Identification and Control, 2007, Vol. 28, pp. 1-12. ISSN 0332-7353.

[34] ANNA WITKOWSKA, MIROSŁAW TOMERA, ROMAN 'SMIERZCHALSKI., "A backstepping approach to ship course control." nternational Journal of Applied Mathematics and Computer Science, 2007, Vol. 17, pp. 73-85.

[35] Xiuwen Liu, Cui Xie, Yicheng Jin, Yong Yin., "Construct Low-Cost Multi-Projector Tiled Display System for Marine Simulator." Hangzhou, China : s.n., 2006. 16th International Conference on Artificial Reality and Telexistence (ICAT'06). pp. 688-693. ISBN: 07695-2754-X.
[36] Alexandre G. Ferreira, Renato Cerqueira, Waldemar Celes Filho, Marcelo Gattass., "Multiple Display Viewing Architecture for Virtual Environments over Heterogeneous Networks." s.l. : IEEE Computer Society Washington, DC, USA, 1999. XII Brazilian Symposium on Computer Graphics and Image Processing. pp. 83 - 92 . ISBN:0-76950481-7.

[37] Transas Marine Limited., "Potential Incident Simulation, Control and Evaluation System." Transas. [Online] [Cited: May 06, 2010.] http://www.transas.com/products/simulators/sim_products/pisces/.

[38] Fu, Ching-Tang Chou and Li-Chen., "Ships on Real-time Rendering Dynamic Ocean Applied in 6-DOF Platform Motion Simulator." Taichun, Taiwan : s.n., 2007. CACS International Conference.

[39] K J Rawson, E C Tupper., Basic Ship Theory. s.l.: ButterworthHeinemann. Vol. 1. ISBN 0750653965.

[40] Y Nakayama, R F Boucher., Introduction to Fluid Mechanics. s.l. Butterworth-Heinemann, 1998. ISBN 0340676493.

[41] Auke Visser's International Esso Tankers site., Esso Osaka - (19731985). [Online] [Cited: May 06, 2010.] http://www.aukevisser.nl/inter/id427.htm.

[42] The Specialist Committee on Esso Osaka., "Final Report and Recommendations to the 23rd ITTC." 2002. 23rd International Towing Tank Conference.

[43] Mc Taggart, Kevin., Improved Maneuvering Forces and Autopilot Modelling for the ShipMo3D Ship Motion Library. s.l.: Defence R\&D Canada - Atlantic, 2008. DRDC Atlantic TM 2008-162.

[44] McTaggart, Kevin., Simulation of Hydrodynamic Forces and Motions for a Freely Maneuvering Ship in a Seaway. s.l.: Defence R\&D Canada - Atlantic, 2005. DRDC Atlantic TM 2005-071.

[45] The MathWorks, Inc., The MathWorks. [Online] [Cited: May 06, 2010.] http://www.mathworks.com/.

[46] Tristan P'erez, Mogens Blanke., Simulation of Ship Motion in Seaway. Technical Report EE02037.

[47] Lewis, Edward V., Principles of Naval Architecture. s.l. : Society of Naval Architects and Marine Engineers , 1989. ISBN-0939773-00-7.

[48] IXSEA Ltd., OCTANS - SURFACE GYROCOMPASS \& MOTION SENSOR . [Online] [Cited: May 06, 2010.] http://www.ixsea.com/en/products/1/octans.html.

[49] William B. Lamport, M Josefsson., "THE NEXT GENERATION OF ROUND FIT-FOR-PURPOSE HULL FORM FPSOS OFFERS ADVANTAGES OVER TRADITIONAL SHIP-SHAPED HULL FORMS." New Orleans, Louisiana USA : ASME, 2008. DeepGulf Conference.

[50] Jayasagara class patrol craft. [Online] [Cited: May 06, 2010.] http://en.wikipedia.org/wiki/Jayasagara class patrol_craft.

[51] Object-Oriented Graphics Rendering Engine. [Online] [Cited: May 06, 2010.] http://www.ogre3d.org/.

[52] Philip Greenwood, Jesse Sago, Sam Richmond, Vivi Chau., "Using game engine technology to create real-time interactive environments to assist in planning and visual assessment for infrastructure." Cairns, Australia : s.n., 2009. 18th World IMACS / MODSIM Congress.

[53] Philip Paar, Katy Appleton, Malte Clasen, Maria Gensel, Simon Jude , Andrew Lovett., "Interactive Visual Simulation of Coastal Landscape Change." 2008. Digital Earth Summit on Geoinformatics.

[54] British admiralty charts. [Online] [Cited: May 06, 2010.] http://www.mdnautical.com/britishadmiraltycharts.htm.

[55] Satelight Image Source . [Online] [Cited: May 06, 2010.] http://earth.google.com/.

[56] Autodesk., The Autodesk 3D Studio Max Documentations. [Online] [Cited: May 06, 2010.] http://usa.autodesk.com/.

[57] The Ogremax Documentations. [Online] [Cited: May 06, 2010.] http://www.ogremax.com/.

[58] V Rankov, R J Locke, R J Edens, B Vojnovic., "An algorithm for image stitching and blending." Proc SPIE (2005). 2005, Vol. 5701, pp. 190-199.

[59] Aldo A. McLean, William E. Biles., "A SIMULATION APPRAOCH TO THE EVALUATION OF OPERATIONAL COSTS AND PERFORMANCE IN LINER SHIPPING OPERATIONS." s.l. Winter Simulation Conference, 2008. Winter Simulation Conference ISBN:978-1-4244-2708-6 